Liverpool ; Dr. Joseph Tait, resident secretary in Scotland, Pharmaceutical Society; Mr. D. R. Wilson, bacteriologist, Moredun Institute, Animal Diseases Research Association, Gilmerton, Edinburgh.

The Council of the Royal Society of Edinburgh has awarded the Keith Prize for the period 1939-41 jointly to Prof. E. T. Copson, University College, Dundee, and to Prof. W. H. McCrea, Queen's University, Belfast, for their papers in the Proceedings of the Society within the period of the award, and in recognition of their valuable contributions to the theory of Riemannian space and general relativity.

The Neill Prize for the period 1939-41 has been awarded jointly to Dr. P. C. Koller, Institute of Animal Genetics, University of Edinburgh, for his contributions to cytology; and to Dr. W. J. McCallien, Department of Geology, University of Glasgow, for his contributions to the tectonic geology of the Scottish Highlands.

\section{Philosophy of the Physical Sciences}

IN his recent presidential address to the Royal Society of Edinburgh on "Some Disputed Questions in the Philosophy of the Physical Sciences", Prof. E. T. Whittaker discussed the problem raised by the Greeks and at the present time vigorously debated by Eddington, Jeffreys, Milne, Jeans, Dingle and others, on the respective shares of reason and observation in the discovery of the laws of Nature. He recalled that the Greeks considered that geometry could be built up completely apart from observation, but that Aristotle at least (and much later Aquinas) held that other sciences must be built on experience. Later progress showed that geometry also must be regarded as a branch of experimental knowledge, and from the time of Newton until now, the principle that science rests fundamentally on observation and experiment has been unchallenged. Now, however, certain thinkers-notably Milne and Eddingtonhold that the laws of Nature can be derived without recourse to observation. Prof. Whittaker points out that many important branches of physics can be deduced from single "postulates of impotence" ; for example, the whole of relativity theory follows from the postulate that it is impossible to detect absolute motion. Such postulates are not the direct result of experiment, though they are generalizations from experiment. Milne's "cosmological principle" is in form a postulate of impotence, but it is assumed without experimental support. Fddington's "epistemological principles", however, are different, but Prof. Whittaker is not convinced that they have any basis outside experience. His verdict on Eddington's claim is : "Not Proven".

The concentration into postulates of impotence of the experimental contribution to physical laws is a very suggestive generalization, and it is an interesting conjecture that the whole of physical law might ultimately be derived by reason from a single postulate of impotence. At the same time it would be a mistake to suppose that anything significant can come out of a pure negation. A postulate of impotence is indebted to experience not only for failure to violate it but also for an indication of the positive thing which in the stated circumstances it denies. The impossibility of spontaneous passage of heat from cold to hot bodies implies the fact of experience that heat can pass between bodies; the denial of absolute motion would be without meaning if we had no experience of relative motion; and so on. It is a pity that Prof. Whittaker's address was prepared before Eddington's recent change of front. In the "Philosophy of Physical Science" he wrote : "For the truth of the conclusions of physical science, observation is the supreme Court of Appeal" (p. 9), and accepted the statement that physics is "the rational correlation of experience" (p. 185). In NATURE of October 25, 1941, however, he stated, in reply to the objection that the supreme Court of Appeal might decide against the rationally derived laws, that "the fundamental ('inviolable') laws are not assertions about experience". It appears, therefore that Prof. Whittaker has been analysing a superseded claim.

\section{Science as a Force of Freedom}

THE value of science as a force of freedom was emphasized by Mr. G. B. Lal in a recent address to the New History Society, New York. The power of science is unique. Great men of science have world wide influence. But they have achieved such influence without the use of the slightest violence or fraud. People have killed each other for religion; but not for science. In science there is a peculiar and most important pattern of freedom. Science develops only when the scientific worker has enough social power to enable him to do his work utterly unhampered. Also, every development in science releases new forms of social energy. Most people respect science because of its practical importance, as shown by the machines of scientific inventors, the conquest of diseases, the piling up of profits in industries, the production of military weapons, rapid transportation and communication. But the most important thing about science is its method. The scientific method is the most efficient use of human intelligence for the discovery of truth.

\section{Physics of a Transmission Line}

Prof. W. M. Thornton has published a thoughtprovoking paper with the above title ( $J$. Inst. Elec. Eng., 88, Pt. II, No. 6, Dec., 1941) in which he deals with the fundamental and, in part, unknown field of electromagnetic study underlying the many technical and economic problems entailed in the design, construction and operation of electric transmission lines. $\mathrm{He}$ pays special attention to the electromagnetic mechanism by which electric and magnetic stresses in space combine so that the energy of electric strain passes continuously along the insulating medium around the wires. Remarking that this, the Poynting flux flow, is the least known of the physical actions in transmission, Prof. Thornton discusses the transfer of potential energy along a transmission line by strain of the insulation, extending the theory to the supply of energy to electric lamps, heaters and rotating machinery. Following a lucid explanation of Poynting's theorem, physical analogies are given to the resistance, inductance and capacitance of a transmission line, resistance being regarded as the coefficient of dissipation of energy, inductance as inertia, and capacitance as elasticity; an invisible shaft of energy which would be perfectly rigid in the absence of inductance and capacitance rotates about the conductors of a three-phase system at the supply frequency.

Suggesting that there may still be engineers who regard the purity of the copper of their machines or cables as more important than insulation quality, the paper proceeds to a discussion of the function of 
insulation and the complex nature of corona, pointing out the limiting influence of the latter on voltage, while emphasizing that from the same aspect moisture effects are more important than corona. Prof. Thornton closes with a brief mention of the mechanical design of insulators, remarking that the complex physical stresses, electrical and mechanical, in a suspension insulator form a difficult three-dimensional problem which may well repay further investigation.

\section{Technical Developments in Broadcasting}

Is his chairman's address to the Wireless Section of the Institution of Electrical Engineers ( $J$. Inst. Elec. Eng., 89, Pt. 1, No. 13; 1942) H. Bishop of the B.B.C., in reviewing the general trend of progress up to the outbreak of hostilities, gave first an outline of the underlying principles involved in the acoustic design of studios and mentioned some of the difficulties associated with the microphone. Programme input equipment and the control and measurement of the volume of broadcast programmes were discussed, special mention being made of the war-time application of sound recording and reproduction by the B.B.C. Tribute was paid to the Post Office in connexion with the use of telephone networks as music, control and television circuits. Transmitter design, modulation and frequency control and power plant received considerable attention. The influence of ionospheric storms on short-wave propagation was discussed, and a section included on the application and control of frequency measurement stations. The address closed with a reference to post-war receivers, suggesting that greater measures of standardization and reliability are needed to achieve the success so dependent on public interest.

\section{Meteorology of Rhodesia}

THE Meteorological Report of the Rhodesia Meteorological Service for the year ended June 30, 1940, has the signature of R. A. Jubb, acting chief meteorologist, owing to the appointment of the chief meteorologist, Mr. N. P. Sellick, to the post of deputy director of meteorological services of Southern Africa, with his headquarters at Pretoria. Since the period covered by the report includes the outbreak of war, to the normal activities of the service was added the work of reorganization to meet naval and military war-time requirements and the restrictions imposed by the censorship on the publication of weather reports and forecasts. In consequence of this handicap there are few new developments to record, but on the other hand the collection of meteorological statistics, including hourly readings of various instruments at the main observatories, was maintained without any general interruption, and continued to prove of great value to engineers and to various industrial enterprises. These statistics, in tabular form, occupy the greater part of the report. The addition of thermographs to many climatological stations was found to be useful both in tracing the travel of weather systems and as a check on the readings of thermometers. The seasonal forecast of the general rainfall by a formula taking into accounc the values of various meteorological elements at 'action centres' in distant regions was continued. A deficiency of $4.8 \mathrm{in}$. was predicted for 1939-40, but an excess of 3.3 in. was experienced. In the eleven years for which the results of such forecasts are available there were only two other comparable failures, whereas successful predictions were made in seven years, the most notable being an almost exact prediction of the outstandingly heavy rainfall of 1938-39, which amounted to an excess of 12.2 in. compared with the predicted excess of $11.8 \mathrm{in}$. The utility of these forecasts now appears to have been firmly established,

\section{Social Implications of Dietetics}

Addressing the Rugby Branch of the Association of Scientific Workers on February 19 on the "Social Implications of Dietetics", Prof. V. H. Mottram examined the possibility of securing the basic dietetic essentials for healthy living in present circumstances. He stated that an investigation in Leicester as to the present cost of providing as close as possible an approximation to the British Medical Association estimate would be $11 s$. $3 \frac{1}{2} d$. per head per week. He compared with this the allowances being given for evacuated children and the dependants of Service men. Prof. Mottram suggested that only by special provision of family allowances on a fairly generous scale will it be possible to ensure that children will receive their needful intake of food essentials, and emphasized that the logic of free education leads on to the provision of free food for children and adolescents.

The future agricultural policy of Great Britain, Prof. Mottram said should be directed to growing more 'protective' foods-such as dairy foods and market garden produce-for which the soil and climate are best fitted. In this he was sustained by the agreement of Sir John Russell, Sir John Orr and Mr. A. G. Street. On the question of health in war-time, while pointing out that the tuberculosis-rate is rising, he agreed that there seems to be no deterioration and even some improvement in general health. This he attributed, not to any beneficial effects of rationing, but to better and more food being consumed by the millions now employed who have previously been unemployed, and by the millions now in the Army who are better fed than before. His conclusion was that little can be done in war-time to improve diet, though the provision of concentrates might be helpful.

\section{Banana Research in Trinidad}

Prof. C. W. WARdLaW, Barker professor of cryptogamic botany in the University of Manchester, read a paper on banana research in the Imperial College of Tropical Agriculture, Trinidad, at the Royal Society of Arts on February 24. After emphasizing the merits of the Jamaica banana or Gros Michel as a commercial variety, Prof. Wardlaw discussed its susceptibility to Panama disease, caused by the soil-borne fungus Fusarium oxysporum cubense. A three-fold research scheme to deal with this was organized by the College in collaboration with the Royal Botanic Gardens, Kew. Prof. Wardlaw then indicated some of the practical and scientific results obtained from this research scheme. Hybridization experiments and storage investigations were also described. Prof. Wardlaw was closely associated with these researches while on the staff of the Imperial College of Tropical Agriculture. Readers will recall the excellent series of three articles by him on the banana in Central America in NaTure (147, 313, 344, $380 ; 1941)$; and now they are recommended to read the present address, which covers the whole field and which will be published in due course in the Journal of the Royal Society of Arts. 